\title{
Correlation between Physical Activity and Quality of Life in Schizophrenic Patients
}

\author{
Tanvi Deepak Shah and Sukhada Prabhu
}

\begin{abstract}
Aim: The aim of the study was to assess and find correlation between physical activity and quality of life in patients diagnosed with Schizophrenia. Method: An observational study was carried out using International Physical Activity (IPAQ) and SF - 36 Quality of life questionnaires in 40 schizophrenic patients from two different rehabilitation Centre's. Results: It was found that $97.5 \%$ patients had total PA level below 2500 METs. Whereas all of them had good to moderate total QOL scores. It was also found that there was no correlation between total PA and total SF-36 scoring. Conclusion: Patients with Schizophrenia need accurate monitoring of PA and QOL to avoid the negative shortcomings and also to help prepare a proper treatment program for them.

Tanvi Deepak Shah

BPT

D.Y. Patil School of Physiotherapy

D.Y. Patil deemed to be University

Nerul, Navi Mumbai,India

E-mail: tanvi20shah5@gmail.com

Sukhada Prabhu

Assistant Professor

Department of Kinesiotherapeutics \& Physical Diagnosis

D.Y. Patil School of Physiotherapy

D.Y. Patil deemed to be University

Nerul, Navi Mumbai,India

E-mail: sukhada.prabhu@dypatil.edu

Key Words: Schizophrenia, Physical activity, Quality of life, IPAQ, SF-36

DOI: DOI: 10.18376/jesp/2020/v16/i2/157451
\end{abstract}

\section{Introduction}

Schizophrenia is a mental disorder that affects how a person thinks, feels, and behaves (NIMH 2019). Of the psychoses, schizophrenia has received the greatest attention in terms of research certainly because of the dramatic and devastating effects it has on an individual's quality of life and their prospects for employment, marriage and parenthood (David and Roger 2019). Schizophrenia is a severe and debilitating disorder, which affects general health, functioning, autonomy, subjective wellbeing, and life satisfaction of those who suffer from it (Strassnig et al., 2014). The symptoms of schizophrenia are conventionally divided into positive symptoms (an excess or distortion of normal functioning) and negative symptoms (a decrease or loss of functioning). Positive symptoms Delusions and Hallucinations (NIMH 2019).Negative symptoms - Impairment or loss of volition, motivation, and spontaneous behavior. Loss of awareness of socially appropriate behavior and social withdrawal. Flattening of mood, blunting of affect, and anhedonia. Poverty of thought and speech (NIMH 2019). Cognitive symptoms - Poor "executive functioning" (the ability to understand information and use it to make decisions). Trouble focusing or paying attention Problems with "working memory" (the ability to use information immediately after learning it) (NIMH 2019). 


\section{Journal of Exercise Science \& Physiotherapy Vol.16 No.2 (July to December) 2020 ISSN: 0973-2020 (Print) $\mathrm{I}_{2} \mathrm{OR}$ Impact Factor $=6.850 \quad$ ISSN: 2454-6089 (Online)}

Psychomotor symptoms are also common in schizophrenia. While the increased psychomotor difficulty is related with negative symptoms, the excessive motor activity itself seemingly without purpose is more often associated with positive symptoms. Disturbances of psychomotor activity can range from complex motion patterns such as catatonic states, to simple isolated movements in posture, mannerisms and stereotypes (Gomes et al., 2016). Individuals with schizophrenia are more sedentary than the general population (Beebe et al., 2013). A sedentary lifestyle is a major contributor to disability and death, and includes diabetes mellitus, cancers, cardiovascular and obstructive pulmonary disease (Gomes et al., 2016).It is worth to note that there is an association between sedentary behavior [that is time spent sitting or lying] and the increased incidence of metabolic syndrome (Ford et al., 2005), as well as neuro cognitive deficits (Leutwyler et al., 2004). The physical activity is defined as any bodily movement produced by skeletal muscles resulting in energy expenditure. Exercise is a subset of PA that is planned, structured and repetitive bodily movement performed to improve or maintain one or more components of physical fitness (Caspersen et al., 1985). Regular PA improves oxygen transportation, decreases blood pressure, cholesterol and triglycerides, and consequently, improves QOL (Beebe, et al., 2005). There are various measures to measure physical activity. They can be subjective and objective. Objective measures like pedometers and accelerometers can be used to measure PA, but due to the cost constraints, we didn't use them. Whereas subjective measures in the form of questionnaires are more cost effective and easier to administer. Forms like IPAQ long form and short form, duke's physical activity questionnaire etc. In the present study the IPAQ long form questionnaire was used because it has proved to be a more reliable and valid tool to measure total PA in schizophrenic patients (Faulkner et al., 2006). Quality of life is defined by the World Health Organization as "Individuals' perceptions of their position in life in the context of the culture and value systems in which they live, and in relation to their goals, expectations, standards, and concerns."Quality of life is a subjective, multidimensional concept that defines a standard level for emotional, physical, material and social well-being. It serves as a reference against which an individual or society can measure the different domains of a personal life. In schizophrenia, QOL may represent the functional effect itself and its treatment as perceived by the patient (Awad and Voruganti 2012). The psychopathology has substantial impact on QOL, wellbeing and social and occupational function and thus creates a considerable socioeconomic burden (Abouzaid et al., 2014 ; Siegel et al., 2006). In schizophrenia, QOL is associated with emotional distress, depressive and negative symptoms, low self-esteem and self-efficacy, as well as, lack of emotional and social support (Ritsner 2014; Fitzgerald et al., 2001). Financial problems, as well as social stigmatization and discrimination are associated with low QOL (Fitzgerald et al., 2001). In addition, hypertension, obesity and metabolic syndrome, pharmacotherapy, depression, pain, disease duration and psychopathology severity are related with low QOL (Kolotkin et al., 2008 ; Allison et al., 2003 ; Fitzgerald et al., 2001). Various measures like HRQOL, WHOQOL-BREF, SF - 36, Mc Gill QOL questionnaire can be used to assess QOL in patients. In the present SF - 36 questionnaires was used because it has been proven to reliable and valid to assess QOL in schizophrenic patients (Russo et al., 1998). There is scientific evidence that antipsychotic medications can produce side effects such as, overweight and obesity. Additionally, these individuals usually have smoking habits, inadequate diets and insufficient levels of daily physical activity (PA) for maintenance of general health. These factors lead to a reduction in the ability to perform activities of daily living, which can promote financial difficulties, social discrimination, as well as the reduction in their quality of life (QOL) (Almeida et al., 2013). Although QOL is a complex construct influenced by multiple factors, these recent findings positively support PA as an important modifiable factor affecting patients' QoL (Chang et al., 2013). The aim of this study was to assess PA and QOL in schizophrenic patients and to correlate them. 


\section{Journal of Exercise Science \& Physiotherapy Vol.16 No.2 (July to December) 2020 \\ ISSN: 0973-2020 (Print) I I OR Impact Factor $=6.850 \quad$ ISSN: 2454-6089 (Online)}

\section{Materials and Method}

The present study was approved by the ethical committee of School of Physiotherapy at D.Y.Patil University, Nerul, Navi Mumbai. The study design was an observational study. The forty $(\mathrm{N}=40)$ patients were selected with a convenient sampling method. They were taken from two Rehabilitation Centre's namely Sunshine Wellness rehabilitation Centre, Vasai and Goel Rehabilitation Centre, Andheri, Mumbai. The consent was taken from the patients along with the demographic details. Data was collected with the help of IPAQ and SF-36 questionnaires in the form of interviews for most of the patients. The data obtained was subjected to statistical analysis using SPSS software. Pearson's correlation test was used to find out correlation between PA and QOL. The questionnaires used were as follows.

$I P A Q$ - It is a 27 -item self-reported measure of physical activity used for individuals between the age group of 15 to 69 years. It assesses the types of intensity of PA and sitting time that people do as a part of their daily lives are considered to estimate total PA in MET mins/week and time spent sitting. It consists of five parts- Job related physical activity, Transportation physical activity, Housework, house maintenance, and caring for family, Recreation, sport and leisure time physical activity, Time spent sitting .

$S F-36$ - It is a 36 item, patient reported survey of patient health. It consists of 2 components (physical and mental health) divided into eight domains namely Physical functioning- Role limitations due to physical problems, Emotional well being, Role limitations due to emotional health, Energy/ fatigue, Pain, Social functioning, General health.

Scoring is 0 to 100 . Higher the score better is the health status. The scale is proved to have good reliability (alpha $=<.70)$ and validity for schizophrenic patients.

Inclusion criteria

- Patients diagnosed with schizophrenia based on the DSM 5 criteria.

- Patients between the age group of 18 to 69 years.

- Patients in the prodromal stage or in the early acute stages of Schizophrenia.

- Patients on proper medications.

- Patients willing to participate in the study.

Exclusion criteria

- Patients in the latent or relapsed stage of schizophrenia.

- Patients with severe cognitive symptoms.

- Patients whose symptoms are not under control even when they are on medications.

- Patients who are unwilling to participate in the study.

Results

In the present study, forty schizophrenic patients were assessed for their PA and QOL with help of IPAQ long form and SF - 36 questionnaires. The aim of the present study was to assess PA and QOL of schizophrenic patients and to correlate PA and QOL. It was found that majority patients had low levels of physical activity and moderate to good quality of life based on scoring of the questionnaires. It was also found that there was no correlation between total PA levels and total scoring of SF-36. However, we found out that role limitations due to physical functioning, emotional wellbeing and energy domains of SF-36 were positively correlated with total PA levels whereas the rest of the domains were negatively correlated.

\section{Discussion}

According to Figure 1, fifty eight percent (58\%) subjects of the present study were males whereas forty two (42\%) were females. The reason for this may be that the incidence of schizophrenia is two to three times higher among males than in females (Iacono and Beiser 1992). Based on Figure 2, $7.5 \%$ of the subjects belonged to age group of 15 to 25 years, $40 \%$ of them belonged to the age 


\section{Journal of Exercise Science \& Physiotherapy Vol.16 No.2 (July to December) 2020 ISSN: 0973-2020 (Print) $\quad \mathrm{I}_{2} \mathrm{OR}$ Impact Factor $=6.850 \quad$ ISSN: 2454-6089 (Online)}

group of 26 to 35 years, $37.5 \%$ belonged to 36 to 45 years of age, whereas $15 \%$ of them belonged to age group of 46 to 75 years of age. This may be due to the fact that, although schizophrenia can occur at any age, the average age of onset tends to be in the late teens to the early 20s for men, and the late 20s to early 30s for women (www.nami.org). Based on Figure 3, 97.5\% of the patients had total PA levels below 2500 METs whereas $2.5 \%$ had total PA levels between 4000 - 4500 METs. On analysis it was found that most of the patients belonged to the low PA category based on the guidelines of IPAQ. This was consistent with a Portugal study where they concluded that outpatients with schizophrenia have lower PA levels (Gomes et al., 2016). Out of their study population; only $25 \%$ of them had regular PA as compared to normal individuals whereas the rest of the $75 \%$ had low PA. There have been various other studies that have proved that the PA of schizophrenics is quite low (Gomes et al., 2016). Specifically, in the present study, we believed that there are few main reasons to justify these results such as - Physical activities were limited to recreational walks in the park or aerobic sessions of an hour on daily basis, they weren't subjected to the routine activities carried out by the others. Therefore, this can be the major contributing factor in the low PA of these patients.PA is important for individuals with schizophrenia, since they show high levels of inactivity and it is one of the important modifiable CVS risk factors and strongly associated with mortality (Bobes et al., 2007). Based on the SF - 36 scoring, $57.5 \%$ had scoring between 50 and 80 whereas the remaining $42.5 \%$ had the scoring between 80 and 100 . Figure 4 shows total scoring of SF-36. Also, on calculating the mean values for all domains (physical and mental) of SF-36, we found them to be between 63 and 87, as shown in Figure 5. Figure 4 and Figure 5 shows that the quality of life of schizophrenic patients in our study was moderate to good. However, the results of our study contradicts previous other studies that state individuals with schizophrenia experience poor quality of life. This may be due to the fact that all individuals with schizophrenia in our study lived successfully in the community and were included in psycho social rehabilitation units. The goal of these units is to help patients to overcome the psychosocial integration difficulties through the participation in daily activities Therefore, we believe that the participation in psychosocial rehabilitation programs may had a positive influence in the QOL of the group with schizophrenia. Also, we cannot neglect the fact that although the subjects were on medications, their psychopathology might have hindered while answering the questions. Delusions of grandeur may also have a big part for the QOL score to be so high. We also correlated the various domains of SF-36 questionnaire with total physical activity levels. Table 2 shows that PA was negatively correlated to physical function domain whereas positively correlated to role limitations due to physical problems, this maybe because all facilities were provided to the patients in the Centre, therefore no extra hardships were faced by them for normal daily activities there by reducing the PA levels. PA was also negatively related to role limitations due to emotional health domain. Therefore, proving that emotional health didn't depend on the patient's total physical activity. PA is positively related to the energy/fatigue domain, thus we can say that the patient's energy determines the total physical activity levels. As our subjects had low PA levels, their energy levels also might be low, and they must feel fatigued more often.

The correlational status of emotional health, emotional well - being, social functioning and general health domains are in line with another study which also concluded that light PA was negatively associated with mental health domains (www.nami.org). Also, there was no correlation between total PA levels and total SF 36 scoring, this may be due to the fact that physical activity levels were obtained subjectively with help of questionnaires rather than objectively using accelerometers or calorimeters or pedometers. Antipsychotic drugs have been known to help manage the schizophrenic symptoms, but they also have various side effects. Patients with adverse events reported significantly less satisfaction with subjective feelings and general activities than patients without adverse events. The side effects with the most significant negative impact were sleep 


\section{Journal of Exercise Science \& Physiotherapy Vol.16 No.2 (July to December) 2020 ISSN: 0973-2020 (Print) I IOR Impact Factor $=6.850 \quad$ ISSN: 2454-6089 (Online)}

disturbance, fatigue, tachycardia, tremor, sexual dysfunction, headache, polyuria, dizziness, hypertension/hypotension, dyskinetic movements, and constipation/diarrhea. These in turn negatively impact on the PA levels and QOL (Bobes et al., 2007). Recent studies suggest that PA can lower the risk of cardio-metabolic disease and improve cardiopulmonary fitness but also alleviate negative symptoms and cognitive decline in patients with schizophrenia (Firth et al., 2015). Considering that adequate PA can reduce the risk of cardiovascular disease and premature mortality, attempts are needed to increase PA in patients with schizophrenia. As mentioned above, PA is also closely related to mental health, including self-esteem, social functioning, and quality of life (Lee et al., 2018). Various studies demonstrate that aerobic exercise significantly reduces psychiatric symptoms, potentially improves mental and physical quality of life and reduces metabolic risk and weight. No adverse effects of it are observed (Vera-Garcia et al., 2015). In the last two decades, there has been increasing interest in quality of life in schizophrenic patients, since schizophrenia is a severe, disabling, lifelong disorder, associated with severe social and occupational dysfunction (Bobes et al.,2007).

\section{Conclusion}

Therefore, it is important to monitor the physical activity levels as well as quality of life in patients with schizophrenia to avoid the negative shortcomings like obesity, depression, sedentary behavior. It will be helpful in devising an accurate patient centered healthcare program. It might help the patient in various aspects of his life and will help in reducing the devastating effects of inactivity and that of their shunned social life. New psychosocial approaches need to focus on PA, help this population to better perceive these benefits in daily lives, in order to improve QOL. Integration of physiotherapy in the multidisciplinary approach to treat the schizophrenic patients has proven to be very beneficial.

Acknowledgements: I am thankful to Dr. Unnati Pandit, Professor and Director of the School of Physiotherapy, D.Y.Patil University, Navi Mumbai who has given me the permission to initiate the project in this institution and has given her valuable advice and help throughout this project. I'm also really thankful to Dr.Goel for giving me permission to collect my research data from schizophrenic patients in her Rehabilitation center's in Andheri and Vasai, Mumbai. Needless to say, that all my study subjects also deserve an incredible word of thanks for their participation and helping us to make this study a success.

Table 1. Descriptive Statistics

\begin{tabular}{|l|c|c|c|c|c|}
\hline & $\mathbf{N}$ & Minimum & Maximum & Mean & $\begin{array}{c}\text { Std. } \\
\text { Deviation }\end{array}$ \\
\hline $\begin{array}{l}\text { Total Physical Activity } \\
\text { in METS }\end{array}$ & 40 & 0.0 & 4293.0 & 1584.263 & 667.1630 \\
\hline Physical Functioning & 40 & 10 & 100 & 81.81 & 19.920 \\
\hline $\begin{array}{l}\text { Role Limitations Due To } \\
\text { Physical Problems }\end{array}$ & 40 & 0 & 100 & 64.38 & 36.201 \\
\hline $\begin{array}{l}\text { Role Limitations Due To } \\
\text { Emotional Health }\end{array}$ & 40 & 0.00 & 100.00 & 70.4167 & 38.39506 \\
\hline Energy/Fatigue & 40 & 35 & 100 & 72.56 & 14.909 \\
\hline Emotional Well Being & 40 & 8 & 100 & 79.40 & 17.832 \\
\hline Social Functioning & 40 & 25 & 100 & 84.53 & 16.561 \\
\hline Pain & 40 & 68 & 100 & 88.38 & 10.839 \\
\hline General Health & 40 & 45 & 100 & 73.00 & 12.750 \\
\hline Total Sf 36 Score & 39 & 51.88 & 93.38 & 76.2137 & 12.16874 \\
\hline
\end{tabular}


Journal of Exercise Science \& Physiotherapy Vol.16 No.2 (July to December) 2020 ISSN: 0973-2020 (Print) $\quad I_{2}$ OR Impact Factor $=6.850 \quad$ ISSN: 2454-6089 (Online)

Table 2. Correlation Statistics

\begin{tabular}{|c|c|c|}
\hline Variables & & $\begin{array}{l}\text { TOTAL PHYSICAL } \\
\text { ACTIVITY MET }\end{array}$ \\
\hline \multirow[t]{3}{*}{ PHYSICAL FUNCTIONING } & $\begin{array}{l}\text { Pearson } \\
\text { Correlation }\end{array}$ & -.108 \\
\hline & Sig. (2-tailed) & .507 \\
\hline & $\mathrm{N}$ & 40 \\
\hline \multirow[t]{3}{*}{$\begin{array}{l}\text { ROLE LIMITATIONS DUE TO } \\
\text { PHYSICAL PROBLEMS }\end{array}$} & $\begin{array}{l}\text { Pearson } \\
\text { Correlation } \\
\end{array}$ & .040 \\
\hline & Sig. (2-tailed) & .808 \\
\hline & $\mathrm{N}$ & 40 \\
\hline \multirow[t]{3}{*}{$\begin{array}{l}\text { ROLE LIMITATIONS DUE TO } \\
\text { EMOTIONAL HEALTH }\end{array}$} & $\begin{array}{l}\text { Pearson } \\
\text { Correlation }\end{array}$ & -.236 \\
\hline & Sig. (2-tailed) & .143 \\
\hline & $\mathrm{N}$ & 40 \\
\hline \multirow[t]{3}{*}{ ENERGY/FATIGUE } & $\begin{array}{l}\text { Pearson } \\
\text { Correlation }\end{array}$ & .202 \\
\hline & Sig. (2-tailed) & .212 \\
\hline & $\mathrm{N}$ & 40 \\
\hline \multirow[t]{3}{*}{ EMOTIONAL WELL BEING } & $\begin{array}{l}\text { Pearson } \\
\text { Correlation }\end{array}$ & .021 \\
\hline & Sig. (2-tailed) & .896 \\
\hline & $\mathrm{N}$ & 40 \\
\hline \multirow[t]{3}{*}{ SOCIAL FUNCTIONONG } & $\begin{array}{l}\text { Pearson } \\
\text { Correlation }\end{array}$ & -.064 \\
\hline & Sig. (2-tailed) & .697 \\
\hline & $\mathrm{N}$ & 40 \\
\hline \multirow[t]{3}{*}{ PAIN } & $\begin{array}{l}\text { Pearson } \\
\text { Correlation }\end{array}$ & -.181 \\
\hline & Sig. (2-tailed) & .263 \\
\hline & $\mathrm{N}$ & 40 \\
\hline \multirow[t]{3}{*}{ GENERAL HEALTH } & $\begin{array}{l}\text { Pearson } \\
\text { Correlation } \\
\end{array}$ & -.171 \\
\hline & Sig. (2-tailed) & .292 \\
\hline & $\mathrm{N}$ & 40 \\
\hline \multirow[t]{3}{*}{ TOTAL SF 36 SCORE } & $\begin{array}{l}\text { Pearson } \\
\text { Correlation } \\
\end{array}$ & .000 \\
\hline & Sig. (2-tailed) & 1.000 \\
\hline & $\mathrm{N}$ & 39 \\
\hline
\end{tabular}


Journal of Exercise Science \& Physiotherapy Vol.16 No.2 (July to December) 2020

ISSN: 0973-2020 (Print) $\quad \mathrm{I}_{2}$ OR Impact Factor $=6.850 \quad$ ISSN: 2454-6089 (Online)

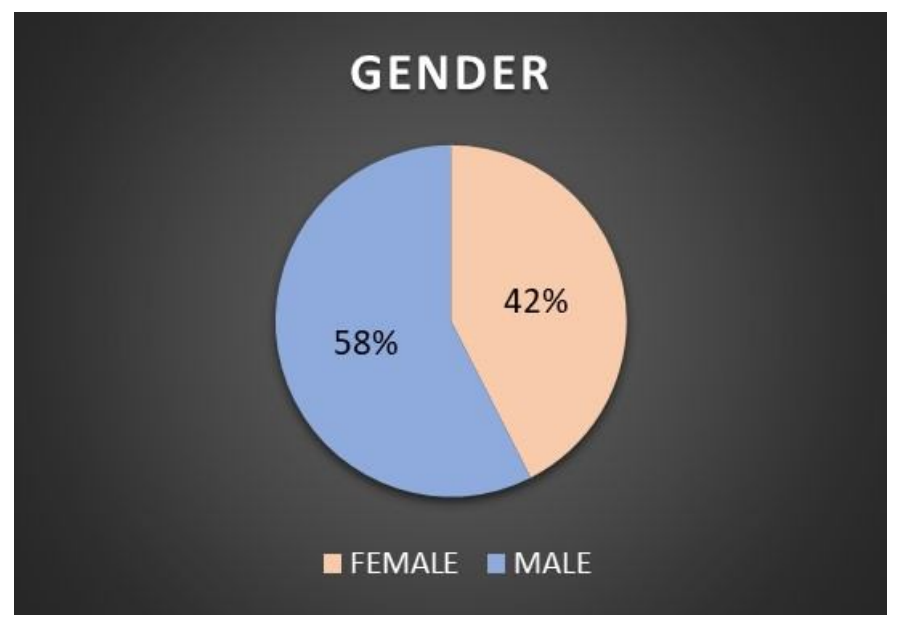

Figure 1. Distribution based on gender

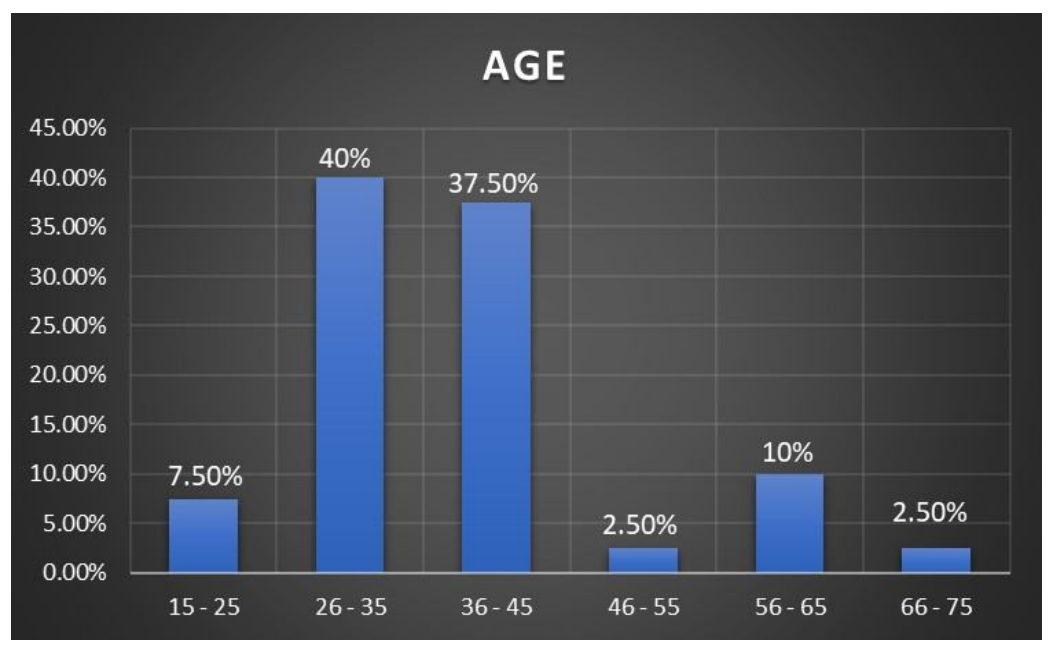

Figure 2. Distribution based on age groups 
Journal of Exercise Science \& Physiotherapy Vol.16 No.2 (July to December) 2020

ISSN: 0973-2020 (Print) $\quad I_{2}$ OR Impact Factor $=6.850 \quad$ ISSN: 2454-6089 (Online)

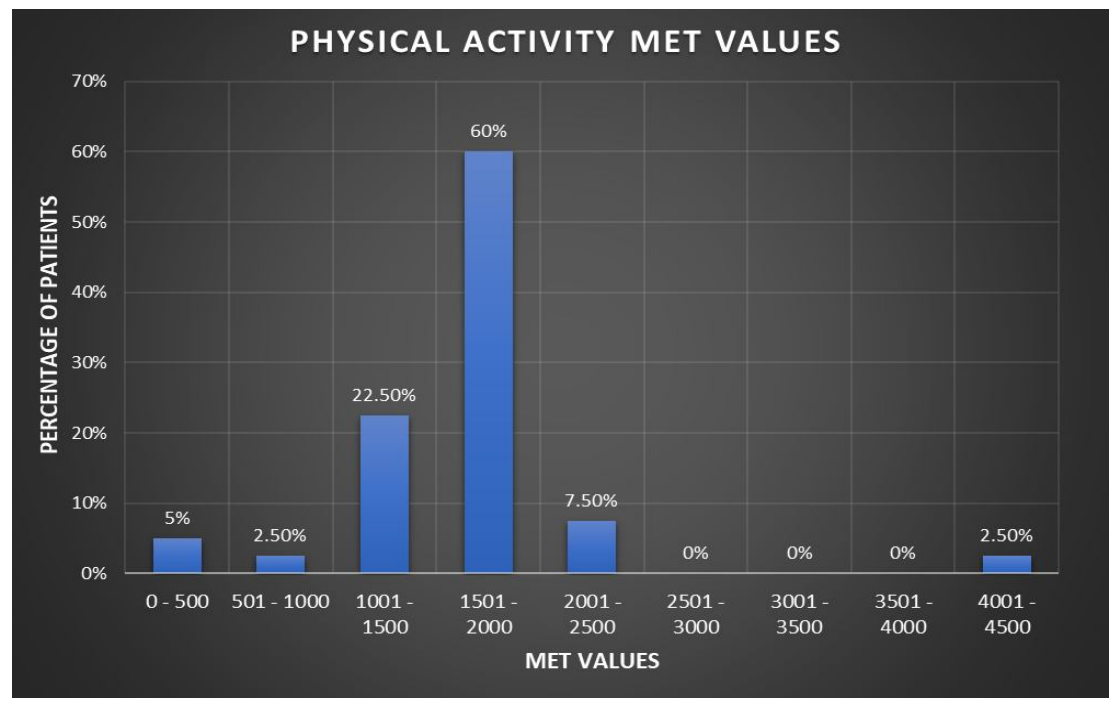

Figure 3. Distribution based on total physical activity levels (METs)

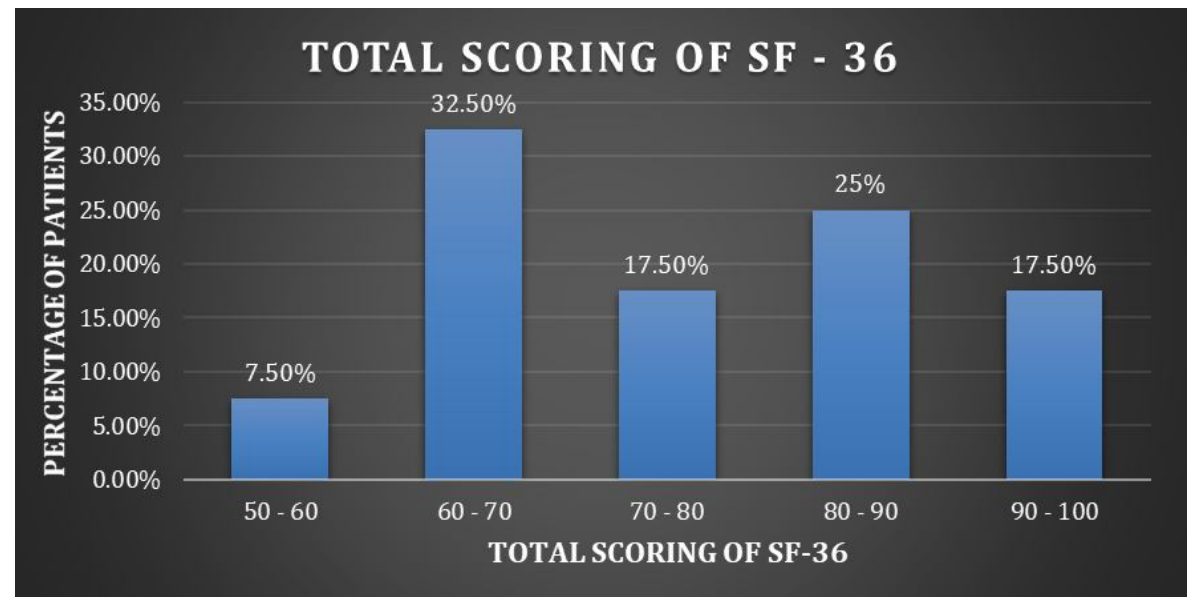

Figure 4. Distribution based on total scoring of SF-36 


\section{Journal of Exercise Science \& Physiotherapy Vol.16 No.2 (July to December) 2020 ISSN: 0973-2020 (Print) $\quad I_{2}$ OR Impact Factor $=6.850 \quad$ ISSN: 2454-6089 (Online)}

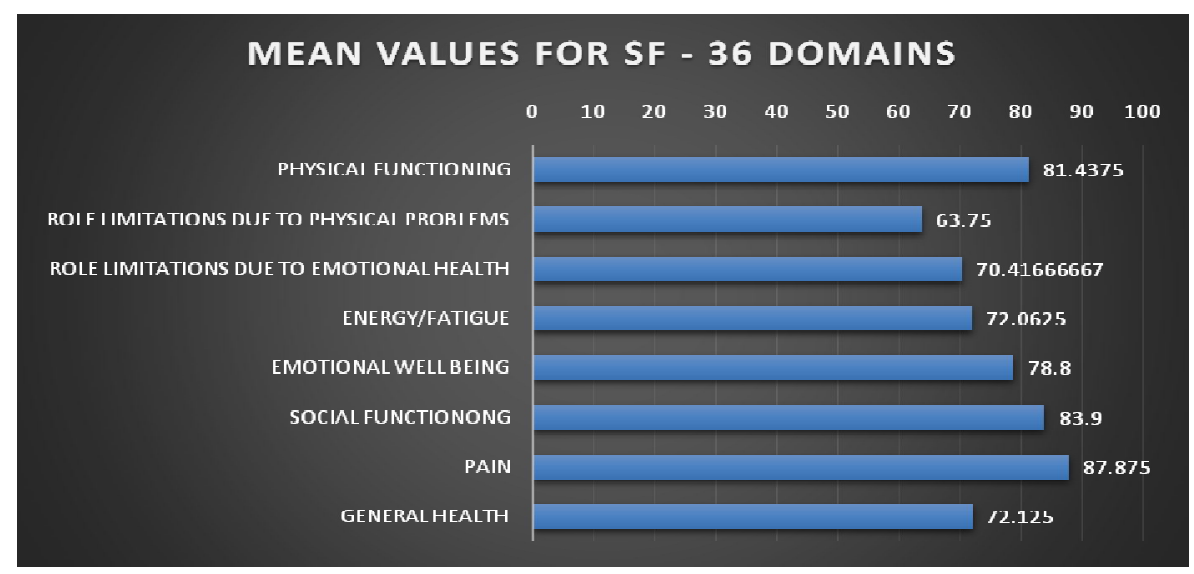

Figure 5. Mean values for SF - 36 domains

\section{References}

Abouzaid, S., Tian, H., Zhou, H., Kahler, K., Harris, M., \& Kim, E. 2014 . Economic Burden Associated with Extrapyramidal Symptoms in a Medicaid Population with Schizophrenia. Community Mental Health Journal 50(1), 51-58.

Allison, D. B., Mackell, J. A., \& McDonnell, D. D.2003.The impact of weight gain on quality of life among persons with schizophrenia. Psychiatric Services 54(4), 565-567.

Almeida, J. G., Braga, P. E., Neto, F. L., \& Pimenta, C. A. M.2013.Chronic pain and quality of life in schizophrenic patients. Revista Brasileira de Psiquiatria 35(1), 13-20.

Awad, A. G., and Voruganti, L. N. P. 2012. Measuring quality of life in patients with schizophrenia: an update. Pharmacoeconomics 30(3), 183-195.

Beebe, L. H., \& Harris, R. F.2013.Description of physical activity in outpatients with schizophrenia spectrum disorders. International Journal Mental Health Nursing 22(5), 430-436.

Beebe, L. H., Tian, L., Morris, N., Goodwin, A., Allen, S. S., \& Kuldau, J. 2005.Effects of exercise on mental and physical health parameters of persons with schizophrenia. Issues in Mental Health Nursing. 26(6), 661-676.

Bobes J, Garcia-Portilla MP, Bascaran MT, Saiz PA, Bousoño M.2007.Quality of life in schizophrenic patients. Dialogues Clin Neurosci 9(2):215-226.

Caspersen, C. J., Powell, K. E., \& Christeson, G. M.1985.Physical Activity, Exercise, and Physical Fitness: Definitions and Distinctions for Health-Related Research. Public Health Reports 100(02), 126-131.

Chang, L.-R., Lin, Y.-H., Wu Chang, H.-C., Chen, Y.-Z., Huang, W.-L., Liu, C.- M., Liu, C.-C., \& Hwu, H.G.2013. Psychopathology, rehospitalization and quality of life among patients with schizophrenia under home care case management in Taiwan. Journal of the Formosan Medical Association 112(4), 208-215.

David Semple and Roger Smyth. 2019. Schizophrenia. Oxford Handbook of Psychiatry. $4^{\text {th }}$ Ed. UK : Oxford University Press. p.262-303

Faulkner G, Cohn T, Remington G.2006. Validation of a physical activity assessment tool for individuals with schizophrenia. Schizophr Res 82:225-31

Firth J, Cotter J, Elliott R, French P, Yung AR. 2015.A systematic review and meta-analysis of exercise interventions in schizophrenia patients. Psychol Med 45:1343-1361.

Fitzgerald, P. B., Williams, C. L., Corteling, N., Filia, S. L., Brewer, K., Adams, A., de Castella, A. R., Rolfe, T., Davey, P., \& Kulkarni, J. 2001.Subject and observer-rated quality of life in schizophrenia. Acta Psychiatrica Scandinavica 103(5), 387-392. 


\section{Journal of Exercise Science \& Physiotherapy Vol.16 No.2 (July to December) 2020 ISSN: 0973-2020 (Print) I I OR Impact Factor $=6.850 \quad$ ISSN: 2454-6089 (Online)}

Ford, E. S., Kohl, H. W., III, Mokdad, A. H., \& Ajani, U. A.2005. Sedentary Behavior, Physical Activity, and the Metabolic Syndrome among U.S. Adults. Obesity Research 13(3), 608-614.

Gomes Eluana, Bastos Tânia, Probst Michel, Ribeiro José C., Silva Gustavo, Corredeira Rui.2016. Quality of life and physical activity levels in outpatients with schizophrenia. Rev. Bras. Psiquiatr 38(2): 157160.

Iacono, W. G. and Beiser, M.1992. Are males more likely than females to develop schizophrenia? American Journal of Psychiatry 149(8), 1070-1074.

Kolotkin, R. L., Corey-Lisle, P. K., Crosby, R. D., Swanson, J. M., Tuomari, A.V., L'Italien, G. J., \& Mitchell, J. E.2008.Impact of obesity on health- related quality of life in schizophrenia and bipolar disorder. Obesit 16(4), 749-754.

Lee SH, Kim G, Kim CE, Ryu S.2018. Physical Activity of Patients with Chronic Schizophrenia and Related Clinical Factors. Psychiatry Investig 15(8):811-817. doi:10.30773/pi.2018.04.15.1

Leutwyler, H., Hubbard, E. M., Jeste, D. V., Miller, B., \&Vinogradov, S.2004. Associations of Schizophrenia Symptoms and Neurocognition With Physical Activity in Older Adults With Schizophrenia. Biological Research for Nursing 16(1), 23-30

NIMH (National Institute of Mental Heatlh).2019. Schizophrenia. https://www.nimh.nih.gov/health/topics/schizophrenia/index.shtml [Retrieved 2019,21 Nov]

Ritsner, M. S. L. A. A. 2014. Predicting10-year quality-of-life outcomes of patients with schizophrenia and schizoaffective disorders. Psychiatry \& Clinical Neurosciences 68(4), 308-317.

Russo, Joan, et al.1998.The MOS 36-Item Short Form Health Survey: Reliability, Validity, and Preliminary Findings in Schizophrenic Outpatients. Medical Care 36(5) 752-756. JSTOR

Siegel, S. J., Irani, F., Brensinger, C. M., Kohler, C. G., Bilker, W. B.,Ragland, J. D., Kanes, S. J., Gur, R. C., \& Gur, R. E.2006.Prognostic variables at intake and long-term level of function in schizophrenia. The American Journal o Psychiatry163(3), 433-441.

Strassnig M, Signorile J, Gonzalez C, Harvey PD. 2014. Physical performance and disability in schizophrenia. Schizophr Res Cogn 1(2):112-121.

Vera-Garcia E, Mayoral-Cleries F, Vancampfort D, Stubbs B, Cuesta-Vargas AI.2015.A systematic review of the benefits of physical therapy within a multidisciplinary care approach for people with schizophrenia: An update. Psychiatry Research 229(3):828-39

www.nami.org/learn-more/mental-health-conditions/schizophrenia

Conflict of Interest: None declared 